Rupkatha Journal on Interdisciplinary Studies in Humanities (ISSN 0975-2935), Vol. 10, No. 1, 2018 Special Issue on "Interrogating Cultural Translation: Literature and Fine Arts in Translation and Adaptation" In collaboration with the Department of English, Amrita Vishwa Vidyapeetham Guest-edited by Dr. Hari M G, Amrita Vishwa Vidyapeetham, Coimbatore, India DOI: https://dx.doi.org/10.21659/rupkatha.v10n1.16 Full Text: http://rupkatha.com/V10/n1/v10n116.pdf

\title{
Writing the Nation in Rushdie's Midnight's Children: a Dialectical Interplay of Literary and Cinematic Text
}

\author{
Simran Preet $\operatorname{Kaur}^{1}$ \& Kamaldeep Kaur ${ }^{2}$ \\ ${ }^{1}$ Assistant Professor, SMVD University. Email: simranpreetsmvdu@gmail.com \\ ${ }^{2}$ Assistant Professor, GDC, Udhampur. Email: kamaldeepsmvdu@gmail.com
}

Received December 21, 2017; Revised January 30, 2018; Accepted February 4, 2018; Published February 14, 2018.

\begin{abstract}
The Adaptation of literary text is a significant endeavor that becomes a critical effort at revisiting the classics in the area of popular culture. In reworking of the classics, the dialogues are enunciated with an altered script while the narrative becomes more or less consistent. Cinematic as well as theatrical adaptations have proved to be an effective media of transposing meaning across historical times and cultures as they assist in reliving the text, making it a more inclusive enquiry. The present research is based on the hypothesis whether the film adaptation of classic manifests as a parody of the original text or adds a new facet to its time-tested aura. Further, it revisits the most popular assertion that the reworking of classic in form of its adaptation has been relegated to a cliquish study by literary professionals rather than for mass consumption.
\end{abstract}

Keywords: Adaptation; revisit; classic, reworking, consumption.

\section{Introduction: Adaptation, Author and Authorship}

Growing interest in Salman Rushdie's fictional oeuvre, Midnight's Children can be reflected from the fact that it has been adapted three times, be it in for television in 1998 or for theatre in 2002 or in form of film adaptation in 2012. The film adaptation, being the most recent form proves to be an effective media of transferring a new way of reading, disregarding the previously existing notions of fidelity and equivalence in adaptation studies. The cinematic text centers on the issues like intertextuality, copyright, fidelity, authorship, etc. but these barriers become more or less blurred while focusing upon the fact that the text acts as a potent medium to acquaint the audience with the literature classics. Further, the filmic text also constructs a strong sense of fidelity and equivalence due to the fact that Rushdie himself appears as an authorial voice at the backdrop, directing the sequence of the script. Addressing the boundary that exists between the original and cinematic text, Lucy Fischer interrogates, "what constitutes a cinematic signature or creative marker: does it reside within the script... or in the mise-en-scene...?" (Fischer, 2013, p. 7). Salman Rushdie himself encourages the rewriting of source text into target text while revering it to be an act of "translation, migration and metamorphosis, of all the means by which one thing becomes another" (Rushdie, 2009, n. p.).

(C) AesthetixMS 2018. This Open Access article is published under a Creative Commons Attribution Non-Commercial 4.0 International License (http://creativecommons.org/licenses/by-nc/4.0/), which permits non-commercial re-use, distribution, and reproduction in any medium, provided the original work is properly cited. For citation use the DOI. For commercial re-use, please contact editor@rupkatha.com. 
The inception of cinematic text as a new academic field and further destabilization of the hierarchy that exists between the two art forms has encouraged the wide acceptance of adaptations as source text themselves. Keeping in view the blurring of binaries between the texts, Jack boozer in Authorship in Film Adaptation aptly remarks that adaptation "involves the textual transposition of a single-track medium of published writing into a document that embraces the scenic structure and dramatic codes of the multitrack medium of film.” (2008, p. 1). The research article makes a contribution towards exploration of the cinematic elements present in the text and further negating the critical opinion which disregards film as inferior highlighting the fact that the source text is not a 'touchstone' against which the target text should be kept for its analysis. Likewise, the study is based on following research questions:

a. How are the issues of fidelity and equivalence, which are of paramount significance in adaptation studies, have been justified?

b. Does the author of source text possess any authority while participating in the creation of the target text?

c. What repercussion does the voiceover have on the 'intended audience'?

d. What implications does it have on the audience when some of the prominent characters prevalent in the source text are missing from the target text?

\section{Source Text and Rushdie's Cinematic Technique}

Salman Rushdie's Midnight's Children (1981) with its complexities and allegorical narrative technique reflects author's cinematic awareness and keen interest in providing the thrust to the creative project of film adaptation. The autobiographical novel and its visual medium of film explore the tumultuous journey of the protagonist which has been the journey of a nation. Both the novel and the film can be viewed as an allegory of modern India which reflects the volatile events of the post-independent era. A plethora of critical opinion on the novel convincingly relates it to India as a nation state aptly reflected in the words of Robert Fraser in Lifting the Sentence, "Midnight's Children does not explore India, in some important symbolic sense, it is India" (Fraser, 2000, p. 31).

The novel undoubtedly reflects the cinematic elements in itself, thereby, fetching a route for filmmakers to adapt the text. Rushdie's Midnight's Children attests to his alignment towards cinematic devices because of its non-cohesive narrative and overall fragmentation. It is remarkable to note that Rushdie himself had a long and extensive career in the creative field since 1960 , working as a scriptwriter, performer and as a freelance copywriter for television agencies. This can be one of the prominent reasons for Rushdie's use of cinematic tropes in his narrative language. In the similar vein, D. Rombes's essay on The Satanic Verses (1988) also highlights Rushdie's use of cinematic technique which he uses not only to "create visual images... but also to shape the narrative" (Rombes, 1993, p. 47). Further, he was himself screenplay writer of the 2012 adaptation, stimulating the mutation of text into film. Further, his own views on adaptation process reflects the fact that it is not necessary to adhere to the old school of thought while transferring novel into filmic adaptation as he avers, "Everyone accepts that stories and films are different things, and that the source material must be modified, even radically modified, to be effective in the new medium. The only interesting question are 'how?' and 'how much?' " (Rushdie, 2009, n.p.) In cue with Rushdie's argument, one can trace the visual medium of cinema blended into the narrative. From the beginning of the novel, Saleem uses cinematic technique to 
describe the autobiographical narrative of his family's and India's past. To cite an example, retelling the riots that shake the nation in the years preceding independence, Saleem states,

"Close-up of my grandfather's right hand: nails knuckles fingers all somehow bigger than you'd expect. Clumps of red hair on the outside edges. Thumb and forefinger pressed together ...In short, my grandfather was holding a pamphlet" ( $M C, \mathrm{p} .36)$

Saleem's close-up description of his grandfather as a young man in the narrative is a typical Rushdie style of cinematic description. The structuralist feature of representation is further visible in the cinematic description of the massacre of peaceful protestors at Jallianwala Bagh. The words of Rushdie give a vivid and a visual image of the massacre for the reader. A shift from the past to the present tense employed by the writer further intensifies the visual representation of the scene. Rushdie employs this technique numerous times. To cite another instance is the scene when he describes the simultaneous wanderings of his parents in Delhi, each bent on a different adventure that will have great implications for his story;

"One journey began at a fort; one should have ended at a fort, and did not. One foretold the future, the other settled its geographical location... and here is Amina Sinai beneath the high walls of the Red Fort, ... refusing to wait its turn, is another taxi, pausing outside another fort, unloading its cargo of three men in business suits, each carrying a bulky gray bag under his coat." (MC, p. 104)

As the plot unfolds, the description of the moment when his mother meets Nadir-Qasim many years after her marriage is expressed in a highly romanticised cinematic style where lovers cannot kiss each other so they do it symbolically by kissing the objects,

"Two strangers, each bearing a screen-name... hands raising a half-empty glass of Lovely Lassi; my mother's lips pressing gently, nostalgically against the mottled glass; my mother's hands handling the glass to her Nadir-Qasim; who also applied, to the opposite side of the glass,... the eroticism of the indirect kiss into the green neon dinginess of the Pioneer Cafe" (MC, p. 301).

A brief glimpse at scenes analysed above establishes that Midnight's Children refuses hierarchical categorizations and strict distinctions between art forms by employing both literary and cinematic devices. The words of Saleem Sinai reverberate what Rushdie as a sui generis aims at which is an innovative analogy between the text and its adapted version,

"Reality is a question of perspective; the further you get from the past, the more concrete and plausible it seems-but as you approach the present, it inevitably seems more and more incredible. Suppose yourself in a large cinema, sitting at first in the back row, and gradually moving up, row by row, until your nose is almost pressed against the screen. Gradually the stars' faces dissolve into dancing grain; tiny details assume grotesque proportions; the illusion dissolves-or rather, it becomes clear that the illusion itself is reality..." (MC, p. 229).

Here a parallel is established between the viewing of a film and the telling of the story. As he comes to the end, as he moves closer to the screen, the point at which the meaning of his life should be established, Saleem finds that discovering truth and coming to a final judgment on his times is impossible, although his entire life has been a quest for these certainties. The writing of his autobiography, which should have established these certainties for Saleem, as he minutely scrutinizes his family's history, does not give him what he expects. 


\section{Target Text and Rushdie's Authorial Voice}

To continue with the analysis, the research paper further delves into a comparative analysis of four incidents taken from both text and movie. The artistic narration of filmmakers as an emphatic medium not only reaches a wider audience but also explores the literary essence of the text and unfurls the thematic matter, characters and conflicts. Taking cue from the two schools of thought of film adaptation: the traditional which believed that a film should mirror the original work, the novel, as closely and faithfully as possible and the second with a modern outlook which believed in borrowing certain elements from a novel to be presented in a new way, the aim lies in comparing and contrasting the traditional adaptation of Rushdie's Midnight's Children, focusing on its plot elements. to show how far the movie Starting from the 'Perforated Sheet' to 'Abracadabra', the novel as well as the movie follow the same sequel establishing that the movie is merely a simulacra of the novel and is remarkably faithful to novel in terms of scene order and inclusion of everything that happened "once upon a time" $(M C$, p. 3). Likewise, the backdrop of wars which occurred at some point of time in the history of India occurs simultaneously with the life of Saleem Sinai moves back and forth. In the very beginning of the movie, Saleem links his identity to that of the Nation's identity, the way he does in the source text as when he says, "I was born in the city of Bombay once upon a time. At the precise instant of India's arrival of independence, on the stroke of midnight, I tumbled forth into the world". (MCF oo:33)

Further, the next scene shifts towards Kashmir in 1917 and at the backdrop of the scene, the narrator claims that, "my life really began on the shore of the Dal Lake in Kashmir" (MCF 1:04). Using Salman Rushdie's voice for the purpose of narration at the backdrop in the movie, the filmmaker targets the intended audience. According to Wallace-Wells, Rushdie's voiceover proves to be a blessing in disguise, "Rushdie's voice-of-God role in the film will be seen as a flourish of authorial vanity." (Wallace-Wells, 2013, n.p.). The connection between author and audience is established and reinforced through this 'authorial vanity' of Rushdie. However, there exists linguistic variation in terms of the use of language. The character of Boatman Tai transcends from using English, preferring the Indian language in order to achieve the effect of linguistic social realism. Rushdie himself avers that the novel encourages "chutnification" of English so that the language can be "remade in other images" (Rushdie, 1982, p. 8).

The novel undoubtedly reflects the struggle for identity and the relation of personal life to that of the national history. Likewise, the same has been reconstructed in the film adaptation of the novel. Saleem's birth as he claims in the source text is celebrated across the nation when "newspapers celebrated" his arrival and "politicians ratified" his position. Pt. Nehru hails him as "the newest bearer of that ancient face of India which is also eternally young" ( $M C$, p. 167). As a result Saleem claims, "I had been mysteriously handcuffed to history, my destinies indissolubly chained to those of my country..." (MC, p. 3). By 'handcuffing' Saleem to India, Rushdie not only allows him to identify himself with the nation but also provides him a unique possibility to change the course of India's history. His 'falling apart' literally and not 'metaphorically' is suggestive of his unflinching concern for his nation which although he knows is a 'nation of forgetters'. The survey of nation's evolution occurs through the use of human character, Saleem Sinai, whose birth, appearance and experiences are linked to the evolution and emergence of India as a new nation. His physiognomy is compared to 'the Indian Deccan peninsula hanging down' and the stains and birthmarks on either side of his face are compared to the geographic contours of Western and Eastern wings of Pakistan by his teacher in the 'Human Geography' class when he says, "The hideous face of this primitive creature, it reminds you of? ... This object here is human geography...In the face of this ugly ape you don't see the whole map of India?... See! The 
Deccan peninsula hanging down.... the birth mark on the right is East Pakistan and this horrible stain is West." (MCF 1:01:00)

Further, the most crucial event of death of Pandit Jawaharlal Nehru followed by the succession of Indira Gandhi, who ended the era of Midnight's children by castrating them i.e., depriving them of their powers is very well illustrated in the movie;

"The emergency, everyone called it.... four hundred and twenty of us stood blinking in the sunlight and then dispersed into the healing privacy of the crowd..." (MCF 2:05:00).

All the Midnight's children are forced into sterilization. The razing of slums, the incarceration of opponents, and the torture of detainees is brilliantly captured in a similar manner both in the text and its adapted film. The swapping over of Saleem and Shiva at the time of their birth by Mary Priera has been viewed variedly by numerous critics. Critics view Saleem as a "symbol of departing coloniser" (Vandhana, p. 53) and as a 'hybrid of dubious parentage'(Goonetilleke, p. 28). The film adaptation portrays it poignantly when Mary is engrossed in the thoughts of her lover who proceeds on a mission and declares, "Let the rich be poor and the poor, rich". Driven by these words of their last meeting, the movie highlights,

"Two babies in her hands. Two lives in her power. She did it for Joe. For her own private revolutionary act. Love me Joe was in Mary's mind" (MCF 38:36).

Both in the novel as well as in the movie, Saleem and Shiva stay uninformed throughout. However, they figure out this fact later in the climax. The conversation between them at the end of the movie attests to this fact:

Saleem: I stole your life.

Shiva: Bastard! Rich boy... I am going to take your life away. Bit by bit. Like you took mine. (MCF 2:04:53)

The strong relation between the text and the movie is further illustrated through the perforated sheet which acts as an unfilled void marked by a major form of fragmentation symbolising fragmented India. In the advent of both the novel as well as the movie the encounter of atheistic Aadam Aziz with the religious Reverend woman Naseem is through this sheet only. As Rushdie writes, "My grandfather had fallen in love, and had come to think of the perforated sheet as something sacred and magical, because through it had seen which filled up the hole inside which had been created when he had been hit on the nose by a tussock and insulted by the boatman Tai" (MC, p. 28). This 'sacred' and 'magical' sheet when teased further uncovers the disintegration within the family of Saleem. Commenting on the multiple forms of fragmentation, a noted critic, Michael Gorrain After Empire aptly writes "Saleem's own family history is marked by a parodic version of that fragmentation" ( $M C$, p. 114). One major incident is when the father realizes that Saleem is not his real son. Not ready to accept this ugly truth, he bursts out in fury; "Bastard! Get him out of my sight before I kill him." (MCF, 1:23).

Although the novel creates more or less a personal rapport with the film, there exists one significant variation with respect to the character of Padma, the driving force of Saleem. In film, Padma's questioning voice is replaced into declarative sentences by the voiceover of narrator which is condemned by various critics from gender perspective, claiming it to be because of the authorial ego. The source text has an open end where in Padma is uncertain about what happens to Shiva, "To tell the truth, I lied about Shiva's death... I'm still terrified of him" (MC, p. 510). Conversely, in the film, he dies at the end, portraying the fact that films are rarely open for 
interpretation. Moreover, critics like Ahmed and Joshi have provided a more optimistic view on why Rushdie's authoritative voice is a better replacement for that of Padma's claiming that it makes "feel like Rushdie is sitting next to you in the audience... expecting you to laugh and cry at the right moments" (Ahmed, 2013, n.p.) and suggesting that it is a "masterstroke having Rushdie provide the film's narration. His instantly- recognizable tone reciting his self-penned words render him a comforting guide on this tumultuous journey" (Joshi, 2012, n.p.).

\section{Conclusion: Fidelity and Equivalence}

An exploration of the visual medium of cinema blended into Rushdie's narrative helps in promoting the symbiotic association between both the art forms. Earlier critics regarded adaptation as inferior, as "minor", "subsidiary", "derivative" or "secondary" products, lacking the symbolic richness of the books and missing their "spirit" (Hutcheon XII-XIII). But in the recent decades, there has been a significant shift in the way the phenomenon of adaptation has been regarded. It paraphrases the already existing art to simplify it for the interpreters as given by Bluestone, "What happens therefore, when the filmist undertakes the adaptation of a novel, given the inevitable mutation, is ... is a kind of paraphrase of the novel- the novel viewed as raw material...That is why there is no necessary correspondence between the excellence of a novel and the quality of the film in which the novel is recorded... (Novels into Film, p. 62). In the similar vein, adaptation of Midnight's Children ends up being a cinematic device emphasising that there exists no hierarchy between the two art forms and thereby giving a path for its cinematic adaptation. The cinematic adaptation blurs the boundaries between the text and the film and gives new evidence of the necessity to promote a symbiotic relationship between the film and the text. The move from a traditional academic form of reading literature into a visual medium of watching that literature heightens receptivity stimulates imagination and strengthens power to analyze a broader range of meaningful structures which are offered by works of art particularly in the case of classics of literature. Rushdie's cinematic technique in his narrative and his authorial voice in film diverge from the issues of fidelity, copyright or equivalence and emphasize upon adaptation as "reading, rewriting, critique, translation, transmutation, recreation, transvocalization, transfiguration, actualization, performance, transmodalization, dialogization, cannibalization, reinvoicing" (Stam, 2012-13).

\section{References}

Ahmed, I. (2013). Review - Midnight's Children. Impact: The University of Nottingham's Official Student Magazine, 8 January. Available at: http://www.impactnottingham.com/2013/o1/ review-midnightschildren/ (accessed 11 February 2018).

Bluestone, George. (1957). Novels into Film. Baltimore: Johns Hopkins University Press.

Boozer, J. (2008). Introduction: The Screenplay and Authorship in Adaptation. In: Boozer J (ed.) Authorship in Film Adaptation. Austin: University of Texas Press, 1-30.

Fischer, L. (2013). Body Double: The Author Incarnate in the Cinema. New Brunswick: Rutgers University Press.

Frazer, Robert. (2000). Lifting the Sentence: A Poetics of Postcolonial Fiction. Manchester University Press.

Goonetilleke, D.C.R.A. (1998). Salman Rushdie. London: Macmillan P. Ltd. 
Gorra, Michael. (1997). After Empire. Chicago: University of Chicago Press.

Hutcheon, Linda. (2012). A Theory of Adaptation. London: Routledge.

Joshi, P. (2012). Midnight's Children Review: A Charming Historical Epic. Digital Spy, 24 December. Available at: http://www.digitalspy.co.uk/movies/review/a447149/midnights-childrenreview-acharming-historical-epic.html (accessed 13 February6 2018)

Mehta, D. (dir.). (2012). Midnight's Children (DVD). Canada: David Hamilton Productions.

Parameswaran, U. (1983). "Handcuffed to History: Salman Rushdie's Art”. Ariel 14:34-45.

Parameswaran, U. (2007). Salman Rushdie's Early Fiction. Jaipur: Rawat Publications.

Rombes, N. D. (1993). "The Satanic Verses as a Cinematic Narrative. Literature-Film Quarterly 21(1): 47-53.

Rushdie, Salman.(2006). Midnight's Children. London: Vintage Books.

Rushdie, S. (2009). "A Fine Pickle". The Guardian, 28 February. Available at: http://www.theguardian.com/books/2009/feb/28/salman-rushdie-novels-film-adaptations (accessed 13 February 2018).

Sanga, Jaina C. Salman Rushdie's Postcolonial Metaphors: Migration, Translation, Hybridity, Blasphemy, and Globalization. Westport: Greenwood Press.

Sharma, Vandhana. "Transcreating India: The Nation In Rushdie's Midnight's Children and Arvind Adiga'sThe White Tiger”. Atlantic Critical Review, p. 51-59, April-June 2011.

Stam, Robert. (2002) Film Theory. An Introduction. Oxford: OUP.

Stam, Robert. (2012-13). "Adaptation and the French New Wave: A Study in Ambivalence”. Interfaces 34: 177-197.

Wallace-Wells, D. (2013). Salman Rushdie turns screenwriter for Midnight's Children. Vulture, 21 April. Available at: http://www.vulture.com/2013/o4/salman-rushdie-turns-screenwriter-formidnightschildren.html (accessed 13 February 2018).

Simran Preet Kaur is an Assistant Professor, School of Languages and Literature at Shri Mata Vaishno Devi University. She has submitted her PhD on the portrayal of celluloid females in Hindi Cinema.

Kamaldeep Kaur is an Assistant Professor at Government Degree College, Udhampur. She has submitted her PhD on Linguistic and Socio-Linguistic Variations in Kandi and Pahari Dogri. 